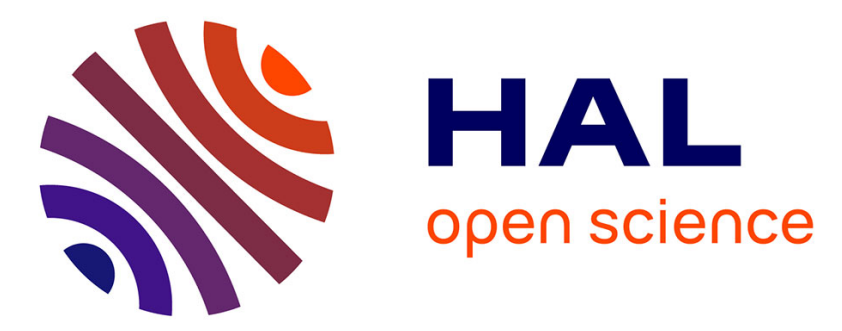

\title{
Enforcing Centralization For Gastric Cancer In Denmark
}

Lone S. Jensen, Henrik Nielsen, Peter Brøndum Mortensen, Hans K.

Pilegaard, Søren Paaske Johnsen

\section{To cite this version:}

Lone S. Jensen, Henrik Nielsen, Peter Brøndum Mortensen, Hans K. Pilegaard, Søren Paaske Johnsen. Enforcing Centralization For Gastric Cancer In Denmark. EJSO - European Journal of Surgical Oncology, 2010, 36, 10.1016/j.ejso.2010.06.025 . hal-00612388

\section{HAL Id: hal-00612388 \\ https://hal.science/hal-00612388}

Submitted on 29 Jul 2011

HAL is a multi-disciplinary open access archive for the deposit and dissemination of scientific research documents, whether they are published or not. The documents may come from teaching and research institutions in France or abroad, or from public or private research centers.
L'archive ouverte pluridisciplinaire HAL, est destinée au dépôt et à la diffusion de documents scientifiques de niveau recherche, publiés ou non, émanant des établissements d'enseignement et de recherche français ou étrangers, des laboratoires publics ou privés. 


\section{Accepted Manuscript}

Title: Enforcing Centralization For Gastric Cancer In Denmark

Authors: Lone S. Jensen, Henrik Nielsen, Peter Brøndum Mortensen, Hans K.

Pilegaard, Søren Paaske Johnsen

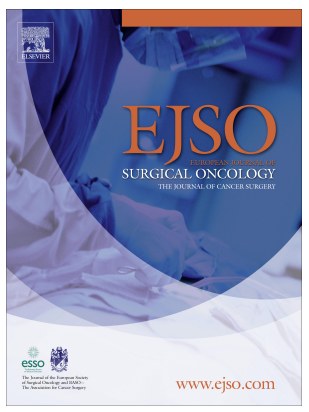

PII:

S0748-7983(10)00201-5

DOI:

10.1016/j.ejso.2010.06.025

Reference: $\quad$ YEJSO 3013

To appear in: European Journal of Surgical Oncology

Received Date: 13 May 2010

Accepted Date: 9 June 2010

Please cite this article as: Jensen LS, Nielsen H, Mortensen PB, Pilegaard HK, Johnsen SP. Enforcing Centralization For Gastric Cancer In Denmark, European Journal of Surgical Oncology (2010), doi: 10.1016/j.ejso.2010.06.025

This is a PDF file of an unedited manuscript that has been accepted for publication. As a service to our customers we are providing this early version of the manuscript. The manuscript will undergo copyediting, typesetting, and review of the resulting proof before it is published in its final form. Please note that during the production process errors may be discovered which could affect the content, and all legal disclaimers that apply to the journal pertain. 


\section{ENFORCING CENTRALIZATION FOR GASTRIC CANCER IN DENMARK.}

Lone S. Jensen ${ }^{\mathrm{a},{ }^{*},}$, Henrik Nielsen ${ }^{\mathrm{b}}$, Peter Brøndum Mortensen ${ }^{\mathrm{c}}$, Hans K. Pilegaard ${ }^{\mathrm{d}}$, Søren Paaske Johnsen $^{\mathrm{b}}$

${ }^{\text {a }}$ Department of Surgery, Aarhus University Hospital, Aarhus, Denmark

${ }^{\mathrm{b}}$ Department of Clinical Epidemiology, Aarhus University Hospital, Aarhus, Denmark

${ }^{c}$ Department of Surgery, Aalborg University Hospital, Aalborg, Denmark

${ }^{\mathrm{d}}$ Department of Thoracic Surgery, Aarhus University Hospital, Aarhus, Denmark

* Corresponding author. Department of Surgery L, Nørrebrogade 44, 8000 Aarhus C, Denmark. Tel: ++45 89493879

E-mail: lonsusje@ rm.dk 


\begin{abstract}
Background: Population-based data on the early postoperative outcome after surgery for gastric cancer are very sparse. We examined the development in the quality of surgery and early postoperative outcomes in Denmark following centralization of gastric cancer surgery and implementation of national clinical guidelines.
\end{abstract}

Methods: All patients in Denmark who underwent resection with curative intent for gastric cancer between 1th. July 2003 to 31 th. December 2008 in one of five university hospitals were registered in a national database. Data on surgical quality and mortality was obtained from the database and compared with the results from the period before centralization (1999-2003).

Results: A total of 416 patients underwent resection in the study period. The risk of anastomotic leakages for the whole period was 5.0\% (95\%CI; 3.2-7.7) compared to $6.1 \%$ (95\%CI; 4.3-8.6) before centralization, whereas the 30-days hospital mortality was $2.4 \%$ (95\%CI;1.2-4.4) compared to $8.2 \%(95 \% \mathrm{CI} ; 6.0-10.4)$ before centralization. In addition, the percentage of patients with at least 15 lymph node removed increased during the study period from 19 in 2003 to 76 in 2008.

Conclusions: Centralization of gastric cancer surgery in Denmark and implementation of national clinical guidelines monitored by a national database was associated with improvements in surgical quality and a substantially lower in-hospital mortality.

Key words: Surgery, Gastric cancer, Volume, Centralization, Clinical guidelines, Audits, Outcome 


\section{Introduction}

Several reports [1-4] have concluded that hospital volume is associated with in-hospital as well as long-term survival following major cancer surgery. Many of the studies have supported the hypothesis that treatment of complex oncologic diseases should be carried out by multidisciplinary teams in high-volume hospitals $[3,5,6]$ thereby reducing in-hospital morbidity and mortality as well as improving long-term survival $[3,7,8]$ ). However, up-to-date population-based data on operative mortality after gastric cancer resection are lacking [9]

In Denmark with approximately 5.5 million inhabitants gastric cancer surgery has previously been carried out in a total of 37 different departments with an overall in-hospital mortality of $8.2 \%$ [10]. However, both in 1996 and in 2001 The National Board of Health recommended [11] reorganization, so that all major surgical procedures were carried out in fewer departments, and especially gastric cancer surgery was recommended to be restricted to five university departments only.

Furthermore, in 1999 the Danish Societies of General and Thoracic Surgery established a working group with the purpose of establishing national clinical guidelines for diagnosis and treatment of cancer in the upper gastrointestinal tract. The guidelines were introduced in 2002 and hereafter a national database was launched in 2003 with the primary aim of monitoring the implementation of the guidelines.

The aim of the present study was to examine the development of the quality of surgery and early postoperative outcomes following the centralization of gastric cancer surgery in Denmark together with the implementation of national clinical guidelines. 


\section{Patients and Methods}

The Danish National Health Service provides tax-supported health care to all Danish residents, including free access to general practitioners and hospitals.

We identified all the patients who had underwent resections with curative intent for gastric cancer between 1th. July 2003 to 31th. December 2008 at one of the five university hospitals in Denmark using the national database on gastric cancer. Data are reported prospectively to the database both when the diagnostic procedures have been completed, when a specific treatment has been finished and at follow up. From 2009, data on oncologic treatment have also been registered. However, these data are not included in the present study.

All Danish citizens are assigned a unique 10-digit civil registration number, which is used in all Danish registries and therefore enables unambiguous, individual-level record linkage between the registries. Using the civil registration number we linked the data from the national database with data from the National Pathology Registry, the National Registry of Patients and the Danish Civil Registration System. The National Pathology Registry holds detailed data on all pathology specimens analysed in Denmark since 1997 [12]. The National Registry of Patients contains data on all discharges from all non psychiatric hospitals in Denmark since 1977 [13]. Data from the National Pathology Registry and the National Registry of Patients were used to ensure the completeness on the national gastric cancer database. The Danish Civil Registration System has maintained electronic records of changes in the vital status of all citizens since 1968 [14]. Data from the Civil Registration System were used to determine survival following gastric cancer surgery.

According to the guidelines the standard surgical procedures are total gastrectomy or distal gastric resections (tumour-free margin of at least five $\mathrm{cm}$ to the proximal resection line). Patients with carcinoma in the gastric cardia are excluded from this study when resection included a partial gastrectomy in combination with resection of a part of the esophagus. In accordance with the 
guidelines established by the Japanese Cancer Association [15] it is recommended, that a D2 lymphadenectomy has to be considered, but without resection of the tail of pancreas and without removal of the spleen. However in accordance with other studies a minimum of 15 lymphnodes should be removed [16], and therefore this is one of several quality of care indicators which is monitored in the national database.

Other quality of care indicators include postoperative morbidity defined as anastomotic leakages, hospital mortality (defined as postoperative death within 30 days) and fiveyear survival after surgery.

Concerning the performance the database provides feed-back on a regular basis (every 3 months) to all of the clinical departments in order to enable local audits. Furthermore, a nationwide audit is held annually resulting in an annual report, presenting the national and department specific data together with comments, conclusions and recommendations from a multidisciplinary steering committee including gastric and thoracic surgeons, pathologists, oncologists, clinical epidemiologists and biostatisticians. The report is distributed to the departments, to all relevant scientific societies and to administrators and is also made publicly available by publication on the internet.

Data from the annual reports from 2003-2008 are used in the present study and are compared with data from the period before centralization and implementation of national clinical guidelines [10]. Results are given with confidence limits of $95 \%$. 


\section{Results}

A total of 416 patients with gastric cancer underwent resection with curative intent during the study period (Table 1). The patients were treated at one of the five university departments from 2003 to 2007. Two departments merged in 2007 and the treatment continued at four departments hereafter. Using data from the National Pathology Registry and the National Registry of Patients we identified four to six patients annually between 2003-2006, who were treated outside the university departments and not registered in the gastric cancer database. Since 2007 no patient has been operated outside the university departments.

Total gastrectomy was performed in 264 patients whereas 152 patients underwent subtotal gastrectomy or a distal gastric resection (Billroth-II-resection) (Table 1).

For the whole period the risk of anastomotic leakage was $5.0 \%$, with $7.2 \%$ for total gastrectomy and $1.3 \%$ for other resections (Tabel 1). The risk tended to decline during the study period. The 30-day hospital mortality was $2.4 \%$ for the whole period with $2.7 \%$ for total gastrectomy and $2.0 \%$ for other resections.

The number of patients who had at least 15 lymph nodes removed increased considerably during the study period as only $19 \%$ fulfilled the indicator requirements in 2003 whereas it was $76 \%$ in 2008 (Fig 1). In 2008, the mean number of nodes removed was 24 (3-52) for total gastrectomy and 15 (1-41) for other resections.

The 5-year survival for patients who had undergone treatment with curative intent was $43 \%(95 \% \mathrm{CI} ; 36-50)$.

A comparison between the results obtained after centralization and the period just before centralization of gastric cancer surgery [10] is shown in Table 2. Significantly $(p<0.01)$ more partial resections compared to total gastrectomy were performed during the period before 
centralization compared to after. Furthermore, the hospital mortality decreased from $8.2 \%$ before centralization to $2.4 \%$ after centralization $(\mathrm{p}<0.05)$. 


\section{Discussion}

This nationwide Danish study of patients undergoing operation for gastric cancer found that centralization of treatment to five (four) university departments together with implementation of national clinical guidelines and the establishment of a national database was followed by clear improvement in surgical quality and in-hospital mortality.

It was remarkable that even if the National Board of Health in agreement with the Danish Surgical Society already in 1996 and again in 2001 [11] recommended that gastrectomies should be performed only at four to five dedicated university departments, this goal was not obtained before the preparation and implementation of national clinical guidelines and a national database for registration.

Already, during the first years after the surveillance of clinical practice and treatment outcome was introduced only few patients were operated outside the recommended departments, and hereafter gastric cancer surgery have been entirely restricted to the university departments as recommended.

In the earlier Danish study [10] it was demonstrated that operations for gastric cancer were performed at up to 37 departments in a five year period (1999 - 2003) before centralization, resulting in a total hospital mortality of $8.2 \%$ with $8.5 \%$ for total gastrectomy and $7.9 \%$ for other resections. No clear trends were observed from 1999-2003 or between the 37 departments. However, only one department operated more than 20 cases/year [10]. Thus, the total number of operations at the department classified as "high-volume" before centralization was not comparable with high-volume centres outside Denmark reporting lower mortality [1,2,7]. Similar observations were made in a Dutch study [17] reporting that all hospitals in one region performed only between 3 
and 13 resections for gastric cancer per year and therefore none of these could be classified as "high-volume" departments. Moreover, it was remarkable that before centralization the operative procedures for gastric cancer consisted of a significantly smaller number of total gastrectomies compared to the period after centralization. The great spread of operations, with few procedures per surgeon, probably resulted in less surgical training, which may explain the preference for a less technical demanding procedure. Also, the introduction of the national clinical guidelines as well as the regularly audits after centralization resulted in high priority and attention towards surgical quality.

Despite centralization, the overall decreasing incidence of gastric carcinoma will result in fewer cases per department over time. We identified a total of 416 operations during $5 \frac{1}{2}$ year study period, which corresponds to a maximum of 80 procedures per year calling for further centralization. However, the "cut-off-point" for the number of gastrectomies to be carried out resulting in improved short-term as well as long-term results cannot be defined exactly. Moreover it has to be taken into consideration that a parallel reduction in gastric resections for benign diseases during the study period also has a big impact on training as it is reducing any potential volume [18]. Other studies have argued that mortality decreased significantly at hospitals performing more than 63 gastrectomies per year [2]. Furthermore, it has been reported that each increase of ten patients in a surgeon's annual caseload is associated with a $41 \%$ lower hospital mortality $[6,19]$.

In the present study the case-load per department actually declined a little every year. However, the surgeons involved in surgery for gastric carcinoma are identical with the surgeons involved in surgery for carcinoma of the esophagus and gastro-esophageal junction. Due to the national clinical guidelines a close collaboration between gastric and thoracic surgeons has been implemented resulting in an increased case-load for similar operations. This might also explain why the short-term results in this study are quite comparable to the best results obtained at high-volume 
international centers $[1,2,7]$. Besides, other factors may also have contributed to the decline in both morbidity (anastomotic leakages) and hospital mortality. In accordance with the reflections made by others this includes the establishment of specialist multidisciplinary teams improving patient selection, as well as great advances in anaesthetic and postoperative care [20]

The extent of lymphadenectomy has throughout the process been monitored as an indicator for surgical quality and in accordance with the classification in the TNM-system we have used removal of a minimum of 15 lymph nodes as quality criteria. Moreover, this is also the minimum of dissected lymph nodes necessary for proper staging and prognosis $[15,21]$. The proportion of patients, who had at least 15 lymph nodes removed increased substantially during the study period. Moreover, the median number of nodes removed was 24 for total gastrectomy at the end of the study period indicating that the recommendations in the guidelines were successfully implemented. The discussion concerning D1 and D2-lymphadenectomy in relation to survival cannot be qualified here as the data required to answer this question were not available.

The overall five year survival rate of $43 \%$ appears to be acceptable. No directly comparable data from Denmark exist from the period before centralization. However, for the period from 1978 to1989 the relative risk of death at 5 years was at least 30\% higher in Denmark compared to the European average [22]. A recent study report that substantial differences in survival after gastric cancer resection within Europe remain [9]. However, the 5 year survival rate in Denmark of $43 \%$ is now quite comparable to the survival rate of other European countries which varies between 24 and $42 \%$ [9].

In conclusion, the process of centralization of all gastric cancer surgery in Denmark to only a few dedicated centers has been combined with the implementation of upgraded national clinical guidelines as well as a national database with systematic and continuous audits and annual 
public reports. Following these initiatives, substantial improvements in surgical quality and patient outcomes have been observed. 


\section{Conflicts of interest}

The authors have no conflict of interest. 


\section{Funding}

None 


\section{References}

1. Birkmeyer JD, Stukel TA, Siewers AE, Goodney PP, Wennberg DE, Lucas FL. Surgeon volume and operative mortality in The United States. N Engl J Med 2003;349:2117-27.

2. Hannan EL, Radzyner M, Rubin D, Dougherty J, Brennan MF. The influence of hospital and surgeon volume on in-hospital mortality for colectomy, gastrectomy, and lung lobectomy in patients with cancer. Surgery 2002;131:6-15.

3. Meyer HJ. The influence of case load and the extent of resection on the quality of treatment outcome in gastric cancer. Eur J Surg Oncol 2005;31:595-604.

4. Skipworth RJE, Parks RW, Stephens NA, Graham C, Brewster DH, Garden OJ et al. The relationship between hospital volume and post-operative mortality rates for upper gastrointestinal cancer resections: Scotland 1982-2003. Eur J Surg Oncol 2010;36:141-47.

5. Sasako M. Role of surgery in multidisciplinary treatment for solid cancers. Int J Clin Oncol 2004;9:346-51.

6. Bachmann MO, Alderson D, Edwards D, Wotton S, Bedford C, Peters TJ et al. Cohort study in South and West England of the influence of specialization on the management and outcome of patients with oesophageal and gastric cancers. Br J Surg 2002;89:914-22.

7. Callahan MA, Christos PJ, Gold HT, Mushlin AI, Daly JM. Influence of surgical subspecialty, training on in-hospital mortality for gastrectomy and colectomy patients. Ann Surg 2003;238:629-39.

8. Brennan MF, Radzyner M, Rubin DM. Outcome-more than just operative mortality. J Surg Oncol 2009;99:470-77.

9. Lepage C, Sant M, Verdecchia A, Forman D. Estéve J, Faivre J and the Eurocare working group. Operative mortality after gastric cancer resection and long-term survival differences across Europe. Br J Surg 2010;97:235-9. 
10. Jensen LS, Bendixen A, Kehlet H. Organisation and early outcomes of major upper gastrointestinal cancer surgery in Denmark 1996-2004. Scand J Surg 2007;96:41-5.

11. Sundhedsstyrelsen. Specialeplanlægning og lands- og landsdelsfunktioner i sygehusvæsenet. København: Sundhedsstyrelsen, 2001.

12. Erichsen R, Lash TH, Hamilton-Dutoit SJ, Bjerregaard B, Vyberg M, Pedersen L. Existing data sources for clinical epidemiology: the Danish national Pathology Registry and Data Bank.

13. Andersen TF, Madsen M, Jorgensen J, Mellemkjoer L, Olsen JH. The Danish National hospital Register. A valuable source of data for modern health sciences. Dan Med Bull 1999;46:263-8.

14. Pedersen CB, Gotzsche H, Moller JO, Mortensen PB. The Danish Civil Registration System. A cohort of eight million persons. Dan Med Bull 2006;53:441-9.

15. Japanese Gastric Cancer Association. Japanese classification of gastric carcinoma; second English edition. Gastric Cancer 1998;1:10-24.

16. Volpe CM, Driscoll DL, Douglass HO Jr. Outcome of patients with proximal gastric cancer depends on extent of resection and number of resected lymph nodes. Ann Surg Oncol 2000;7:132-44.

17. Krijnen P, denDulk M, Kranenberg EM-K, Jansen-Landheer MLEA, van de Velde CJH. Improved survival after resectable non-cardia gastric cancer in the Netherlands: The importance of surgical training and quality control. Eur J Surg Oncol 2009;35:715-20.

18. Munksgaard SB, Fischer A, Rosenberg J. Centralization on fewer surgeons - an example from gastric surgery. Ugeskr Laeger 2007;169:2009-12. 
19. Portanova M, Vargas F, Lombardi E, Mena V, Carbajal R, Palacios N et al. Results of specialization in the surgical treatment of gastric cancer in Peru. Gastric Cancer 2007;10:927.

20. Robertson SA, Skipworth RJ, Clarke DL, Crofts TJ, Lee A, de Beaux AC. Ventilatory and intensive care requirements following oesophageal resection. Ann R Coll Surg Engl 2006;88:354-7.

21. Maruyama K, Sasako M, Kinoshita T, Sano T, Katai H, Okajima K. Pancreas preserving total gastrectomy for proximal gastric cancer. World J Surg 1995;19:532-36.

22. Faivre J, Forman D, Estéve J, Gatta G and the Eurocare working group. Survival of patients with oesophageal and gastric cancers in Europe. Eur J Cancer 1998;34:2167-75. 
Legend to Figure 1

Development in percentage of operations where at least 15 lymph nodes are removed during gastric cancer surgery in Denmark 2003-2008 
Table 1. Gastric cancer surgery activity and outcomes in Denmark between 2003-2008

\begin{tabular}{|c|c|c|c|c|c|c|c|}
\hline & 2003* & 2004 & 2005 & 2006 & 2007 & 2008 & Tota] \\
\hline No. of departments & 5 & 5 & 5 & 5 & 5 & 4 & \\
\hline No. of operations & 37 & 98 & 70 & 82 & 68 & 61 & \\
\hline - Gastrectomy & 21 & 66 & 44 & 45 & 50 & 38 & \\
\hline - Resections & 16 & 32 & 26 & 37 & 18 & 23 & \\
\hline Anastomotic leakages. \%, (95\% CI) & $2.7(0.1-14.2)$ & $10.2(5.0-18.0)$ & $5.7(1.6-14.0)$ & $3.7(0.8-10.3)$ & $2.9(0.4-10.2)$ & $1.6(0.0-8.8)$ & $5.0(3.2-7.7)$ \\
\hline -Total gastrectomy & $0(0.0-16.1)$ & $13.6(6.4-24.3)$ & $9.1(2.5-21.7)$ & $6.7(1.4-18.3)$ & $4.0(0.4-10.2)$ & $2.6(0.1-13.8)$ & $7.2(4.6-11.4)$ \\
\hline -Resections & $6.3(0.2-30.2)$ & $3.1(0.1-16.2)$ & $0.0(0.0-13.2)$ & $0.0(0.0-9.5)$ & $0.0(0.0-18.5)$ & $0.0(0.0-14.8)$ & $1.3(0.2-4.7)$ \\
\hline 30-day Mortality. \%, (95\% CI) & $0.0(0.0-9.5)$ & $2.1(0.3-7.3)$ & $1.4(0.0-7.7)$ & $2.4(0.3-8.5)$ & $4.4(0.9-12.4$ & $3.3(0.4-11.5)$ & $2.4(1.2-4.4)$ \\
\hline -Gastrectomy & $0.0(0.0-16.1)$ & $1.5(0.0-8.0)$ & $0.0(0.0-8.0)$ & $4.4(0.5-15.1)$ & $6.0(1.3-16.5)$ & $2.7(0.1-14.2)$ & $2.7(1.1-5.6)$ \\
\hline -Resections & $0.0(0.0-20.6)$ & $3.1(0.1-16.2)$ & $3.8(0.1-19.6)$ & $0.0(0.0-18.5)$ & $0.0(0.0-18.5)$ & $3.3(0.4-11.5)$ & $2.0(0.4-5.8)$ \\
\hline
\end{tabular}

* Only 6 months 
Table 2. Comparison of gastric cancer surgery in Denmark: 1999-2003 versus 2003-2008

\section{9-2003}

37

537

235

302

$6.1(4.3-8.6)$

$11.1(7.4-15.7)$

$3.2(0.9-4.8)$

$8.2(6.0-10.4)$

$8.5(5.5-13.4)$

$7.9(5.0-11.3)$
2003-2008

5

416

264

152

$5.0(3.2-7.7)$

$7.2(4.6-11.4)$

$1.3(0.2-4.7)$

$2.4(1.2-4.4)$

$2.7(1.1-5.6)$

$2.0(0.4-5.8)$

- Gastrectomy

- Resections

CI) 
Figure 1. Development in percentage of operations where at least 15 lymph nodes are removed during gastric cancer surgery in Denmark 2003-2008.

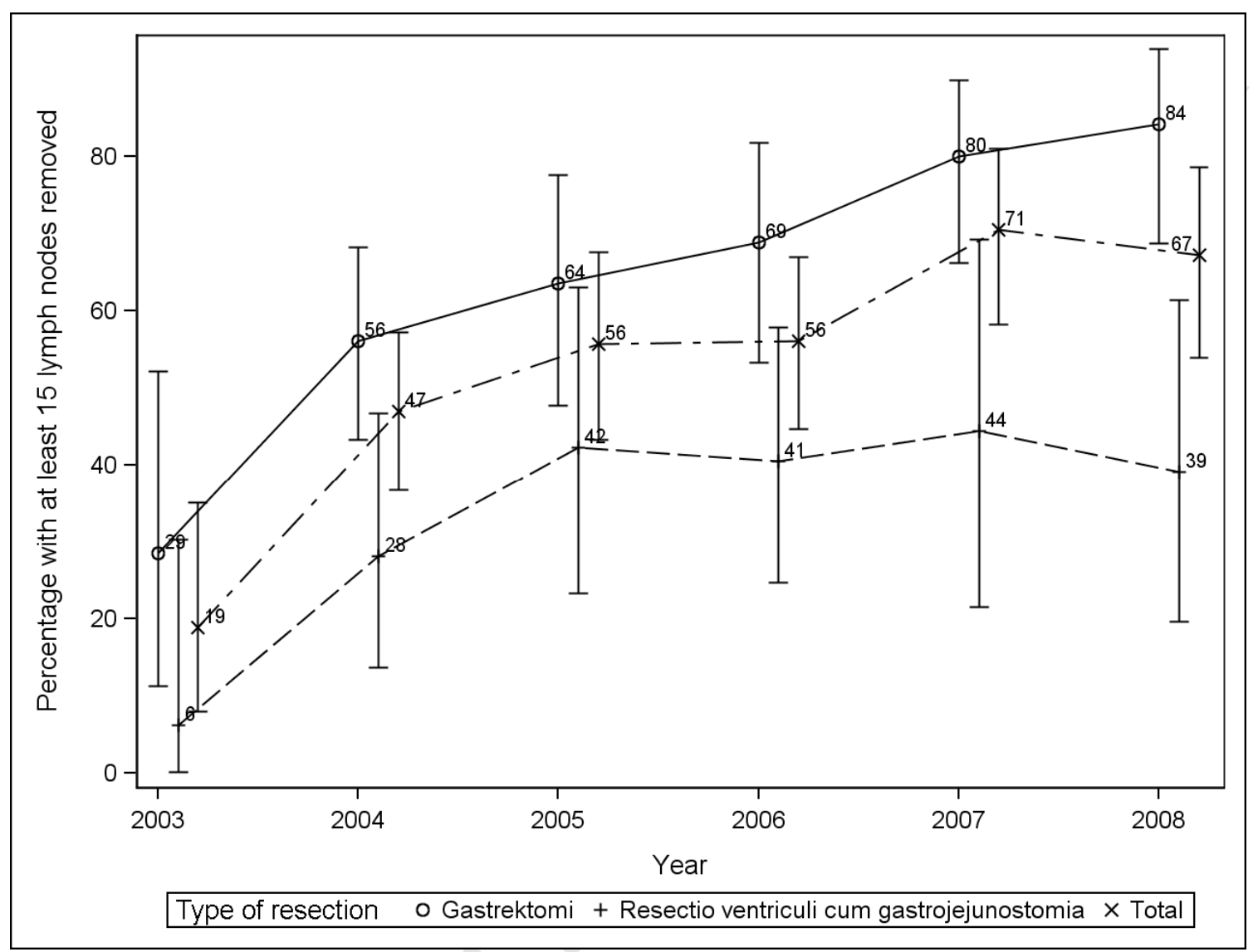

